\title{
Chemical and biological research of Clematis medicinal resources
}

\author{
HAO DaCheng ${ }^{1 *}$, GU XiaoJie $^{1}$, XIAO PeiGen $^{2 *} \&$ PENG Yong ${ }^{2}$ \\ ${ }^{1}$ Biotechnology Institute, School of Environment, Dalian Jiaotong University, Dalian 116028, China; \\ ${ }^{2}$ Key Laboratory of Bioactive Substances and Resources Utilization of Chinese Herbal Medicine of Ministry of Education, Institute of Medicinal \\ Plant Development, Chinese Academy of Medical Sciences, Beijing 100193, China
}

Received August 7, 2012; accepted September 29, 2012; published online December 28, 2012

\begin{abstract}
Clematis is a botanical source for various pharmaceutically active components, which has long been used in conventional medicine since the beginning of Chinese civilization. Increasing interest in Clematis medicinal resources has led to additional discoveries of triterpenoid saponins, flavonoids, coumarins, alkaloids and many other compounds in various Clematis species, and to investigations on their chemotaxonomy, molecular phylogeny and pharmacology. In continuation with our studies on Clematis chemistry and biology, we review the chemistry, chemotaxonomy, molecular biology and phylogeny of Clematis and their relevance to drug efficacy and drug development. Various databases and technology have been used in literature search in order to characterize the global scientific effort. It is essential to study more species for both the sustainable utilization of Clematis medicinal resources and finding novel compounds with potential clinical utility. Systems biology and omics technologies will play an increasingly important role in future medicinal research involving bioactive compounds of Clematis.
\end{abstract}

Clematis, chemical components, chemotaxonomy, molecular taxonomy, medicinal resource

Citation: Hao D C, Gu X J, Xiao P G, et al. Chemical and biological research of Clematis medicinal resources. Chin Sci Bull, 2013, 58: 1120-1129, doi: $10.1007 / \mathrm{s} 11434-012-5628-7$

Clematis is a genus of about 355 species [1] within the eudicot family Ranunculaceae. The genus consists of typically vigorous, woody, climbing vines/lianas, which are mainly distributed in the temperate zone of the north of Earth's equator. Clematis is a botanical source of various pharmaceutically active components, which has long been used in conventional medicine since the beginning of Chinese civilization. Roots, rhizomes and stems of some Clematis species are used to disperse wind-damp, unclog channels and ease pain. Wei Ling Xian and Chuan Mu Tong, recorded in the Chinese Pharmacopoeia (http://www.chp.org.cn/cms/ home/), are the most well-known Chinese herbal medicines obtained from Clematis species. The former is from Clematis chinensis, $C$. hexapetala and $C$. mandshurica, while the latter from $C$. armandii and $C$. montana. Traditionally, Clematis medicine is administered orally to treat sexually transmitted infection, podagra, rheumatoid arthritis, bone disorder, chronic skin diseases, and is used as a diuretic. In

*Corresponding authors (email: hao@djtu.edu.cn; xiaopg@public.bta.net.cn) folk medicine, Clematis is applied to body surfaces for blisters and is also used as a cataplasm to treat purulent infections and ulcers. Different Clematis species may have dissimilar drug effects. Though, it is pretty hard to authenticate Clematis species only by morphology.

To date, at least 30 Clematis species have been characterized for their chemical components. However, it is essential to study more species for both the sustainable utilization of Clematis medicinal resources and finding novel compounds with potential clinical utility. In this brief review, we focus on recent progress in phytochemistry and chemotaxonomy of Clematis, as well as molecular taxonomy and pharmacology.

\section{Methods}

Information was withdrawn from Google Scholar and the journal databases Scopus, PubMed and CNKI (http:// www.cnki.net). 


\section{Chemical components of the genus Clematis}

\subsection{Triterpenoid saponins}

Triterpenes are assembled in a four or five ring configuration of 30 carbons with a number of oxygens appended. The aglycone of Clematis plants is of five-ring triterpenoid oleanane type, including oleanolic type (Figure 1A), olean$3 \beta$, 28-diol type (B), hederagenin type (C) and hederagenin11,13-dien type (D). The conjugated glycosyl groups include glucose (Glc, D configuration), rhamnose (Rha, L configuration), galactose (Gal, D configuration), arabinose (Ara, L configuration), xylose (Xyl, D configuration) and ribose (Rib, D configuration). Since 2009, 19 novel triterpenoid saponins have been isolated from Clematis plants (Table 1). To date, more than 50 oleanolic type prototype saponins, more than 40 hederagenin type prototype saponins and two gypsogenin saponins have been found in Clematis

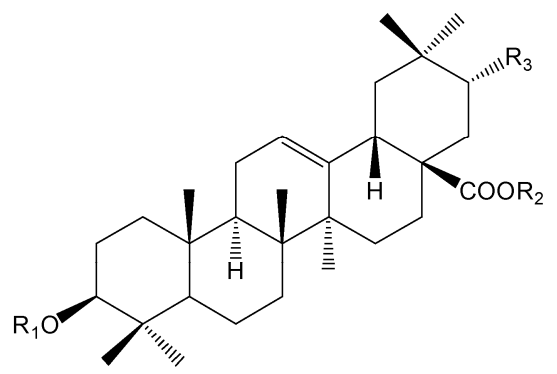

A
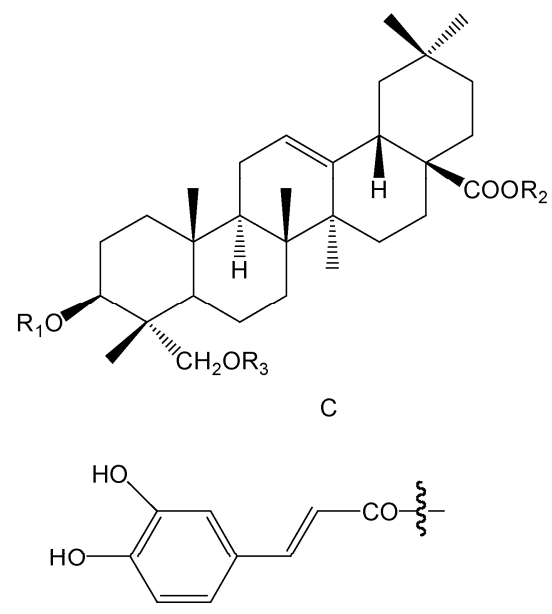

CA

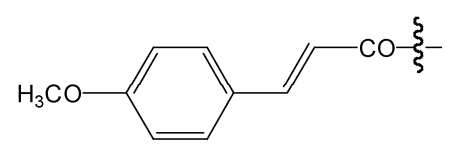

$\mathrm{MC}$ plants [2,3]. Most of these saponins are bidesmosidic, i.e. C-3 and C-28 tie with the oligosaccharide chains. The monodesmosidic saponin is less common. Some oligosaccharide chains are substituted with acetyl, caffeoyl (CA), isoferuloyl (IF), p-methoxy cinnamyl (MC) and 3,4-dimethoxy cinnamyl (DMC) groups (Figure 1). In addition, more than 20 secondary glycosides have been found [2], which lose their C-28 oligosaccharide chains after hydrolysis.

Two new saponins from $C$. argentilucida showed noteworthy cytotoxicity against human leukemia cells, hepatocellular carcinoma cells and glioblastoma cells [3]. Triterpene saponins from $C$. mandshurica inhibit human colon cancer cells [4]. Four triterpene glycosides from C. ganpiniana showed cytotoxicity against cancer cells and antibacterial activity [5]. However, the full potential of the anticancer activity of Clematis saponins cannot be revealed unless

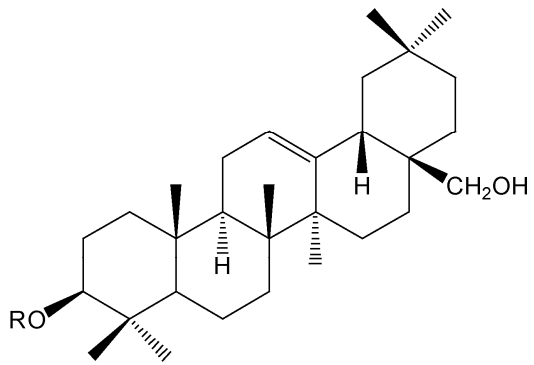

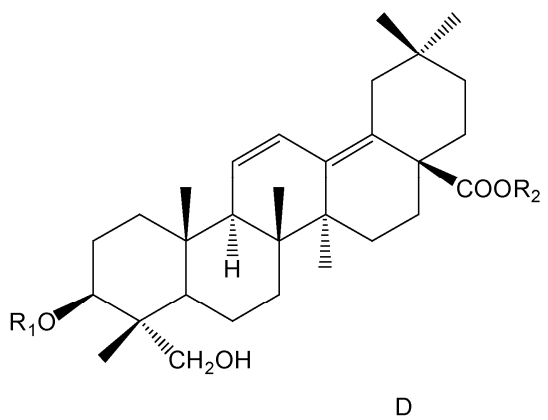<smiles>COC(=O)/C=C/c1ccc(OC)c(O)c1</smiles>

IF

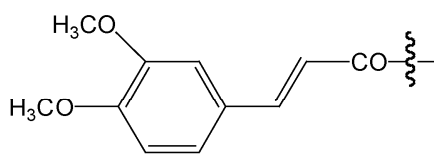

DMC

Figure 1 Aglycone and the substituent linked with glycosyl groups of triterpenoid saponins of Clematis. A, Oleanolic type; B, olean-3 $\beta$, 28-diol type; C, hederagenin type; D, hederagenin-11,13-dien type; CA, caffeoyl; IF, isoferuloyl; MC, $p$-methoxy cinnamyl; DMC, 3,4-dimethoxy cinnamyl. Modified from [2]. 
Table 1 Triterpenoid saponins found in Clematis medicinal plants in recent years ${ }^{\text {a) }}$

\begin{tabular}{|c|c|c|c|c|c|c|}
\hline & Compound & Aglycone & Oligosaccharide chain & Species & Tissue & Reference \\
\hline 1 & $\begin{array}{l}3 \beta \text {-O-[ } \beta \text {-D-ribopyranosyl- }(1 \rightarrow 3)- \\
\alpha \text {-L-rhamnopyranosyl- }(1 \rightarrow 2) \text { - } \\
\alpha \text {-L-arabinopyranosyl] } \\
\text { hederagenin-11,13-dien-28-oic acid }\end{array}$ & $\mathrm{D}$ & 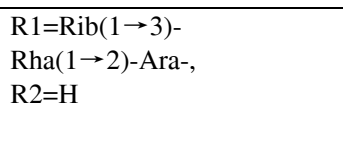 & C. argentilucida & root & [3] \\
\hline 2 & 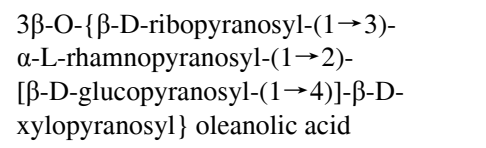 & A & $\begin{array}{l}\mathrm{R} 1=\mathrm{Rib}(1 \rightarrow 3)-\mathrm{Rha}(1 \rightarrow 2)- \\
\mathrm{Glc}(1 \rightarrow 4)-\mathrm{Xyl}- \\
\mathrm{R} 2=\mathrm{H}, \\
\mathrm{R} 3=\mathrm{H}\end{array}$ & C. argentilucida & root & [3] \\
\hline 3 & 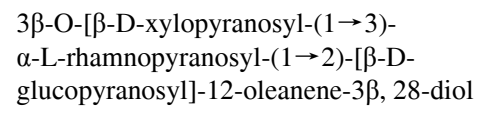 & B & $\begin{array}{l}\mathrm{R}=\mathrm{Xyl}(1 \rightarrow 3)- \\
\text { Rha( }(1 \rightarrow 2)-\text { Glc- }\end{array}$ & C. argentilucida & root & [59] \\
\hline 4 & mandshunosides A & $\mathrm{C}$ & $\begin{array}{l}\text { R1=Glc }(1 \rightarrow 4)- \\
\text { Glc }(1 \rightarrow 4)-\operatorname{Rib}(1 \rightarrow 3)- \\
\text { Rha }(1 \rightarrow 2)-\text { Ara- }, \\
\text { R2=H, } \\
\text { R3=H }\end{array}$ & C. mandshurica & roots, rhizomes & [4] \\
\hline 5 & mandshunosides B & A & 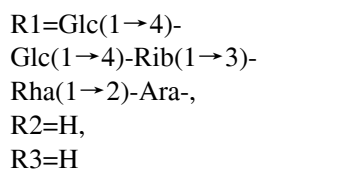 & C. mandshurica & roots, rhizomes & [4] \\
\hline 6 & $\begin{array}{l}\text { 3-O- } \alpha \text {-L-rhamnopyranosyl-( }(1 \rightarrow 6)-\beta \text { - } \\
\text { D-glucopyranosyl- }(1 \rightarrow 4)-\beta \text {-D- } \\
\text { glucopyranosyl- }(1 \rightarrow 4)-\beta \text {-D- } \\
\text { ribopyranosyl- }(1 \rightarrow 3)-\alpha \text {-L- } \\
\text { rhamnopyranosyl- }(1 \rightarrow 2)-\alpha \text {-L- } \\
\text { arabinopyranosyl oleanolic acid } \\
28-O-\beta \text {-D-glucopyranosyl- }(1 \rightarrow 6)-\beta \text {-D- } \\
\text { glucopyranoside (clematomandshurica } \\
\text { saponin E) }\end{array}$ & A & 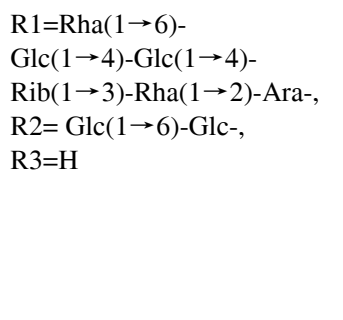 & C. mandshurica & roots, rhizomes & [60] \\
\hline 7 & clematochinenosides A & $\mathrm{C}$ & 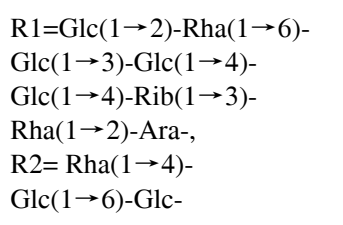 & C. chinensis & roots, rhizomes & [8] \\
\hline 8 & clematochinenosides B & $\mathrm{C}$ & 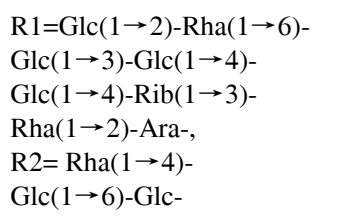 & C. chinensis & roots, rhizomes & [8] \\
\hline 9 & clematochinenosides $\mathrm{C}$ & $\mathrm{C}$ & $\begin{array}{l}\mathrm{R} 1=\mathrm{Rha}(1 \rightarrow 6)-\mathrm{Glc}(1 \rightarrow 4)- \\
\mathrm{Glc}(1 \rightarrow 3)-\mathrm{Glc}(1 \rightarrow 4)- \\
\text { Glc }(1 \rightarrow 4)-\operatorname{Rib}(1 \rightarrow 3)- \\
\mathrm{Rha}(1 \rightarrow 2)-\text { Ara- } \\
\mathrm{R} 2=\mathrm{Rha}(1 \rightarrow 4)- \\
\text { Glc }(1 \rightarrow 6) \text {-Glc- }\end{array}$ & C. chinensis & roots, rhizomes & {$[8]$} \\
\hline 10 & clematochinenosides D & $\mathrm{C}$ & $\begin{array}{l}\mathrm{R} 1=\mathrm{Glc}(1 \rightarrow 4)-\mathrm{Glc}(1 \rightarrow 4)- \\
\mathrm{Rib}(1 \rightarrow 3)-\mathrm{Rha}(1 \rightarrow 2)-\text { Ara- } \\
\mathrm{R} 2=\mathrm{Rha}(1 \rightarrow 4)-\mathrm{Glc}(1 \rightarrow 6)- \\
\text { Glc- }\end{array}$ & C. chinensis & roots, rhizomes & [8] \\
\hline 11 & clematochinenosides $\mathrm{E}$ & $\mathrm{C}$ & $\begin{array}{l}\mathrm{R} 1=\mathrm{Glc}(1 \rightarrow 4)-\mathrm{Glc}(1 \rightarrow 4)- \\
\mathrm{Rib}(1 \rightarrow 3)-\mathrm{Rha}(1 \rightarrow 2)-\text { Ara- } \\
\text { R2= Rha( } 1 \rightarrow 4)-\mathrm{Glc}(1 \rightarrow 6)- \\
\text { Glc- }\end{array}$ & C. chinensis & roots, rhizomes & [8] \\
\hline
\end{tabular}




\begin{tabular}{|c|c|c|c|c|c|c|}
\hline & & & & & & (Continued) \\
\hline & Compound & Aglycone & Oligosaccharide chain & Species & Tissue & Reference \\
\hline 12 & clematochinenosides F & $\mathrm{A}$ & 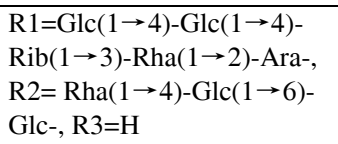 & C. chinensis & roots, rhizomes & {$[8]$} \\
\hline 13 & clematochinenosides $\mathrm{G}$ & $\mathrm{C}$ & 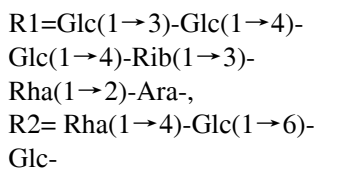 & C. chinensis & roots, rhizomes & {$[8]$} \\
\hline 14 & $\begin{array}{l}3 \beta \text { - }[(\alpha \text {-L-arabinopyranosyl)-oxy }] \\
\text {-olean-12-en-28-oic acid }\end{array}$ & A & $\begin{array}{l}\mathrm{R} 1=\mathrm{Ara} \\
\mathrm{R} 2=\mathrm{R} 3=\mathrm{H}\end{array}$ & C. ganpiniana & roots, rhizomes & {$[5]$} \\
\hline 15 & hederagenin $3 \beta-\mathrm{O}-\alpha$-L-arabinopyranoside & $\mathrm{C}$ & $\begin{array}{l}\mathrm{R} 1=\mathrm{Ara} \\
\mathrm{R} 2=\mathrm{R} 3=\mathrm{H}\end{array}$ & C. ganpiniana & roots, rhizomes & {$[5]$} \\
\hline 17 & $\alpha$-hederin & $\mathrm{C}$ & $\begin{array}{l}\mathrm{R} 1=\mathrm{H}, \\
\mathrm{R} 2=\mathrm{H}, \\
\mathrm{R} 3=\mathrm{H}\end{array}$ & C. ganpiniana & roots, rhizomes & {$[5]$} \\
\hline 18 & 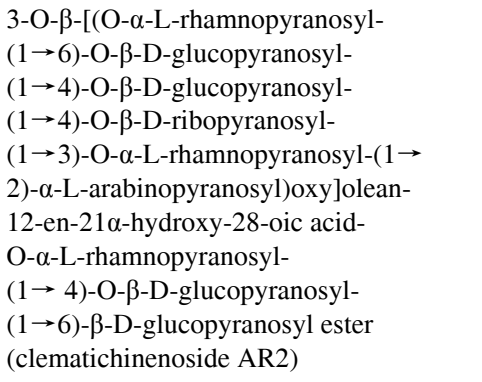 & A & 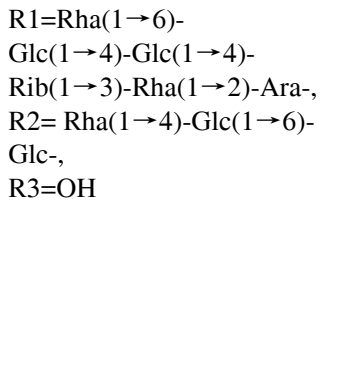 & C. chinensis & roots & {$[61]$} \\
\hline
\end{tabular}

a) Aglycone: A, oleanolic type; B, olean-3ß, 28-diol type; C, hederagenin type; D, hederagenin-11,13-dien type. The locations of R1, R2 and R3 are shown in Figure 1.

much more pharmacological studies are performed.

Traditionally, Wei Ling Xian is used to treat gout, obstinate bi-syndrome, rheumatism, limb numbness, cold pain in the lumbus and knees, and inhibited bending and stretching, etc. Correspondingly, the triterpene saponin AR-6 from $C$. chinensis, a source plant of Wei Ling Xian, has a potential anti-inflammatory effect in rats with collagen-induced arthritis, which inhibits the expression of NF (nuclear factor) $-\kappa \mathrm{B}$ p65 subunits, TNF (tumor necrosis factor) $-\alpha$ and COX (cyclo-oxygenase)-2 [6]. Anti-arthritis effects of AR-6 were related to substantial decline of nitric oxide and TNF- $\alpha$ generated by peritoneal macrophages [7]. In addition, AR-6 appreciably reduced the propagation of synoviocyte. Multiple triterpene saponins of $C$. chinensis showed the potential anti-inflammatory activity with inhibitory activities against COX-1 and COX-2 enzymes [8]. Saponins might be responsible for the inhibition effects of $C$. chinensis on the pro-inflammatory and degradative mediators associated with inflammatory arthritis [9]. The saponin fraction from this plant showed the therapeutic effect on monosodium iodoacetate induced osteoarthritis via sheltering articular cartilage [10]. The release of the full potential of Clematis saponins calls for more extensive and deeper investigations.

\subsection{Flavonoids and anthocyanins}

Flavonoids (or bioflavonoids) are a class of plant secondary metabolites. More than 50 flavonoid compounds have been isolated or detected from Clematis [2,11-14], the aglycones of which are mainly apigenin, kaempfeml, luteolin and quercetin. Sugar moieties are connected to the aglycone through either the oxygen or the carbon atom. Flavonoids of Clematis are categorized, according to chemical structure, into flavonols, flavones, flavanones, isoflavones and their 
glycosides, xanthones and anthocyanidins.

Flavonoids were the major vigorous compounds in four preparative extracts of $C$. terniflora, which might be responsible for reducing sensitivity to painful stimuli and anti-inflammatory effect in rats with carrageenan-induced persistent non-bacterial prostatitis [15]. Anti-inflammatory, pain-relieving and fever-reducing effects of the aqueous extract of $C$. brachiata leaf in male rats may be due in part to the flavonoids [16]. Two flavone C-glycosides from $C$. rehderiana showed potent antioxidant activities [12]. Studies of pharmacological effects of Clematis flavonoids are still in the burgeoning stage.

Twenty-four lignans isolated from Clematis are mainly eupomatene lignans, cyclolignans, monoepoxylignans, bisepoxylignans and lignanolides [2]. Six coumarin compounds have been isolated [2,17]. Eleven alkaloids isolated from Clematis fall into two categories: aporphine and terpenoid alkaloid. Two aporphine alkaloids showed potent antifungal activities [18]. A mannose-binding lectin was separated from C. Montana and showed antiviral and apoptosis-inducing activities [19]. Many other compounds were also isolated from various Clematis species, such as phenolic glycosides [20], volatile oils, triterpenes, steroids, organic acids and their derivatives [21], macrocyclic compounds and others [22]. Their functions and pharmacological effects await further studies.

\section{Chemotaxonomy of Clematis}

The genus Clematis was founded by Linnaeus (1753) with only nine species. The following taxonomic studies increased the number of species: Johnson [23] and GreyWilson [24] independently summarized 314 and 297 species respectively; Wang and $\mathrm{Li}$ [1] depicted 355 species in the new classification of the genus, with around 150 species scattered in China. Four subgenera and ten sections are possibly defined based on a number of essential morphological characters of vegetative and floral organs. The four subgenera are (1) Cheiropsis Peterm.: section Cheiropsis DC.; (2) Clematis Keener \& Dennis: sect. Clematis Tamura, Meclatis Baill., Fruticella Tamura, Naraveliopsis Hand.-Mazz, Viticella DC. and Tubulosae Decne.; (3) Viorna Gray: sect. Viorna Prantl and Archiclemaits Tamura; and (4) Atragene Torr. \& Gray: sect. Atragene DC. A consensus has not been reached on taxonomy, origin and systematic location of this genus.

According to pharmacophylogeny, plants with close genetic relationship are similar in systematic classification and chemical components [25,26]. A chemosystematic study of sect. Viorna, subsect. Viornae was performed using flavonoid distribution patterns [27]. The close relationship between $C$. viorna and $C$. reticulata inferred from their form and structure and geographical allocation was corroborated by the resemblance of their flavonoid profiles. The supposi- tion that C. glaucophylla recently derived from C. versicolor was propped up by their alike flavanoid contours, and the flavonoid multiplicity of $C$. pitcheri samples parallelled their morphological diversity. Flavonoids were used as chemical markers to argue the taxonomy of Ranunculaceae [28]. Feng et al. [29] compared the total flavonoid content of above-ground parts of 11 Clematis species. C. apiifolia leaves had the highest $(5.581 \%)$ total flavonoid while $C$. huchouensis had only $0.195 \%$. The amount of flavones in different species varied much. The cluster analysis based on the flavonoid content set apart the species of the subgenus Clematis and those of the subgenus Viorna, except C. terniflora and C. huchouensis. The aerial parts of $C$. apiifolia and $C$. finetiana could be used for flavonoid drug development.

Plant saponins have been used as chemotaxonomic markers to differentiate various taxa [30-32]. Saponins have been separated from a range of Clematis species [2,11], some of which were used for the chemosystematic study. Muhammad Ishtiaq et al. [33] analyzed 15 populations, representing 12 species of sections Rectae, Clematis, Meclatis, Tubulosae and Viorna, with HPLC (Highperformance liquid chromatography) linked with diode array detector and ESI (electrospray ionization)-MS (mass spectrometry) [34]. A cluster tree was constructed in terms of the distribution of nine saponins and their peak area in the respective species. Three clades were identified. Clade I includes species of sect. Rectae of subgenus Clematis, $C$. finetiana, C. armandii, C. chinensis and C. terniflora, which share five saponins: Huzhangoside B (HGB), Clematichinenoside $\mathrm{C}$ (CCC), Seiboldianoside A (SDA), Huzhangoside D (HGD) and Clematichinenoside B (CCB). Clade II has C. apiifolia, C. argentilucida, C. ganpiniana and $C$. peterae, which belong to sect. Clematis and share saponins CCB, HGD, CCC and HGB. C. henryi of subgenus Viorna shares HGD and Clemochinenoside A (CCA) with $C$. heracleifolia of subgenus clematis and they were grouped together in clade III. This illogicality implies that more saponins and/or other secondary metabolites should be used in the chemotaxonomic analysis. C. huchouensis of subgenus clematis was quite different in total flavonoid [29] and saponin composition, which may have divergent secondary metabolic pathway.

Many studies have investigated the chemical components and bioactivities of Radix et Rhizoma Clematidis (Wei Ling Xian), Caulis Clematidis Armandii (Chuan Mu Tong) and other Clematis species. Triterpenoid saponins are rich in many species (Table 1) and give multiple pharmacological effects. However, raw drugs from other species are also found on the market without verification of efficacy, which may be abused clinically. It is therefore obligatory to resolve the distribution and the contents of the pharmaceutical ingredients in the approved Clematis species for standardization and quality control. Sun et al. [35] developed a straightforward and precise method with HPLC and evapo- 
rative light scattering detection to concurrently resolve five triterpenoid saponins of Clematis. The chemical outlines were used to identify the botanical origin of ten Clematis samples. The contents of HGD and 3-O- $\alpha-\mathrm{L}-\operatorname{ara}(2-1)-\alpha-$ L-rha(4-1)- $\beta$-D-rib pulsatiloside $\mathrm{C}$ were much higher in $C$. chinensis than in other species, which match its efficacy in clinical use. However, these saponins were not found in the above-ground part of $C$. manshurica, suggesting that the aerial fraction of this plant is not suitable as a source of Wei Ling Xian. The saponins were abundant in C. ganpiniana and C. apiifolia var. obtusidentata, which are promising pharmaceutical resources. No triterpenoid saponins were spotted in $C$. armandii, which agrees with previous chemical studies [36]. Thus its drug effects might be associated with other compounds. Five saponins in the roots and stems of C. ganpiniana, C. apiifolia and C. apiifolia var. obtusidentata were more abundant than those in the whole plants except for CCB and CCC of C. apiifolia, which suggests that root and stem might be a better medicinal part than the leaves.

The research group led by Cheng YY and Xiao PG performed a series of Clematis studies. A simple and fast gradient HPLC-MS method was built up and validated for parallel determination of CCB, HGD, CCC and HGB in Radix Clematidis and related species [37]. Optimally, the saponins were well separated in $25 \mathrm{~min}$. The samples hold a wide range $(0.0652-41.7 \mathrm{mg} / \mathrm{g})$ of the four analytes. Radix Clematidis of Tianmu mountain, Zhejiang, China has the highest saponin content $(41.7 \mathrm{mg} / \mathrm{g})$, which was about seven times that in the commercial Radix Clematidis (China market) $(5.80 \mathrm{mg} / \mathrm{g})$. This could be caused by different harvest time and places, suggesting that the source of Radix Clematidis should be defined and curbed. The advantages of this method are good linearity, high sensitivity, precision, accuracy and shorter time, which are obliging in the quality control of Clematis medicine. Triterpenoid saponins were spotted by qualitative HPLC-MS/MS of root and rhizome of 18 Clematis samples and the whole plant of C. puberula var. ganpiniana and $C$. terniflora [38]. The HPLC-MSn identified 17 oleanolic acid or hederagenin saponins, which were used for phylogenetic relationship inference. Three branches were identified based on the 17 peaks. The first branch comprised $C$. lasiandra (subgenus Viorna), $C$. finetiana, $C$. terniflora (whole plant), C. grandidentata and the outgroup species $R$. sieboldii. The next branch contained $C$. chinensis and other seven species of subgenus Clematis. The third cluster consisted of $C$. chinensis and other five species of subgenus Clematis, which are closer to the second cluster than to the first one. The two $C$. chinensis samples did not bunch together, which might be due to different collection time and area. The similar reason is valid for two samples of C. uncinata. HGB could be unequivocally identified in all taxa. All 17 compounds were present in C. puberula var. ganpiniana, $C$. apiifolia and $C$. argentilucida. Further comprehensive study must incorporate more species to check the appropriateness of these molecules for chemotaxonomy of the whole genus. Flavonoids and lignans are important medicinal compounds, which should be further examined to see if they reveal any additional information about the relationships within Clematis.

Proteins and enzymes are the center players of the physiological metabolic pathways of plant cells. Proteins can be biomarkers for cataloging of botanical medicines. Two dimensional gel electrophoresis of leaf protein was useful for examination of the systematic relationship of section Clematis [39]. Significant variety was found among the 1085 spots scored: only 255 spots were shared by all. Nine proteins were only present in $C$. chinensis and absent in $C$. finetiana and $C$. armandii, although they are closer to each other than to other taxa. C. apiifolia, C. peterae, C. argentilucida and $C$. ganpiniana form a group. The genetic distance $0.4-0.45$ and $0.25-0.55$ was observed at intra-subsection level in Clematis and Rectae respectively. Proteomics is a capable taxonomic tool and the differentially expressed proteins provide hints for deciphering the distinction in metabolic pathway of different species. In addition, Shi et al. [40] suggested that the macrocyclic glucosides from C. chinensis, C. armandii, C. hexapetala and C. mandshurica are useful for the chemotaxonomy of sect. Clematis. Even with these studies, the relationships among Clematis species have not been resolved. Molecular methods have to be combined with morphology and chemotaxonomy in the elucidation of the pharmacophylogeny of Clematis.

\section{Molecular taxonomy and molecular phylogeny}

RAPD (random amplification of polymorphic DNA) is a type of PCR reaction, and the DNA sections that are amplified are haphazard [41]. The random primers of 8-12 bp and the genomic DNA template are used in the PCR. By resolving the PCR product patterns, a semi-distinctive profile can be garnered. Among 59 species and 24 varieties in six sections of three Clematis subgenera in Yunnan of Southwest China [42], 56 are endemic to China and 16 are only found in Yunnan. RAPD was used to study 12 Clematis species of Yunnan [43]. Selected ten RAPD primers were used in the random amplification and 89 polymorphic DNA bands were generated. The 12 species can be unambiguously identified. More importantly, the cluster tree basically mirrored the systematic relationship of the involved species. The subgenus Cheiropsis, the most ancient group, are basal to other taxa. C. buchananiana, C. connata and $C$. ranunculoides of subgenus Viorna are basal to subgenus Clematis. Caulis clematidis armandii (Chuan Mu Tong) is a traditional Chinese herbal medicine. The botanical origins of Chuan Mu Tong are the dried stems of C. armandii and C. montana. Chuan $\mathrm{Mu}$ Tong has the effects of heat-clearing, dieresis, activating blood to dredge vessels, and thus is 
used to treat edema, gonorrhea, dysuria, rheumatoid arthritis, amenorrhea and hypogalactia [44]. Due to the morphological resemblance, it is hard to distinguish $C$. armandii and $C$. montana from other Clematis species. The following species are also marketed in China as Chuan Mu Tong [44]: $C$. finetiana, C. kerriana, C. argentilucida, C. peterae, C. apiifolia var. obtusidentata, C. tangutica, C. meyeniana and $C$. uncinata of subgenus Clematis, $C$. leschenaultiana, $C$. lasiandra, C. henryi, C. chrysocoma, C. pogonandra and $C$. trullifera of subgenus Viorna, and C. macropetala of subgenus Atragene. The distribution area of these species is less extensive than that of $C$. montana and $C$. armandii, and some endangered species should be protected [45]. Moreover, although these species are similar to raw plants of Chuan $\mathrm{Mu}$ Tong in drug efficacy, they are sometimes used for specific purposes in some regions and their pharmaceutical ingredients have not been investigated comprehensively. Other plants (e.g. Aristolochia and Akebia) were also mistakenly used as Chuan Mu Tong, which may cause serious toxicity [44]. Guo et al. [46] established a molecular method to discern Caulis clematidis armandii from its frequent contaminants. The RAPD-based dendrogram illustrated that evolutionarily ancient $C$. montana is basal to other taxa and $C$. urophylla and $C$. lasiandra of subgenus Viorna are basal to the seven species of subgenus Clematis, which is not incongruent with RAPD results of $\mathrm{Pu}$ et al. [43]. C. armandii is closer to C. finetiana than to C. argentilucida, C. peterae var. trichocarpa and $C$. apiifolia, which well agrees with the chemotaxonomic results of Muhammad Ishtiaq et al. [33]. Since C. montana and C. armandii are only distantly related, it is crucial to carry out a detailed study to uncover the physical basis of their common drug efficacy. The sequences of two RAPD fragments specific for $C$. armandii and $C$. montana were determined and PCR primers were designed for sequence characterized amplified region (SCAR) markers [46]. The two SCAR markers were specific to both $C$. armandii and $C$. montana but were not present in other species, which can be used in quality control of Chuan Mu Tong. RAPD was also used to study the hybrid origin of descendants from crosses of C. tubulosa and $C$. brevicaudata [47].

ITS (internal transcribed spacer) locates between nuclear ribosomal RNAs (rRNA) of a precursor transcript, which proved valuable for defining relationships among congeneric species and closely related genera [41]. ITS sequences were PCR-amplified from leaf genomic DNA of eight Clematis species of Zhejiang, China [48]. The ITS region varied between 534 and $561 \mathrm{bp}$, with 50 variable sites and 22 parsimony informative sites. On the ITS-based phylogenetic tree, $C$. patens is closer to $C$. patens ssp. Tientaiensis than to $C$. finetiana and $C$. chinensis in one group, while $C$. henryi of subgenus Viorna is closer to $C$. lasiandra (subgenus Viorna) than to C. apiifolia and C. uncinata of subgenus Clematis in the other group. ITS2 is a part of ITS, which is shorter and easier to amplify. The ITS2 region of Wei Ling
Xian and its adulterants varied between 220 and 230 bp [49]. On the ITS2-based phylogenetic tree, $C$. chinensis is closer to $C$. hexapetala than to $C$. mandshurica. These official species of Wei Ling Xian form one cluster, while $C$. lasiandra of subgenus Viorna is closer to $C$. pogonandra (subgenus Viorna) than to C. uncinata (subgenus Clematis), which does not contradict with ITS results [48]. With ITS2, it is also easy to differentiate Wei Ling Xian and plants of Sarcandra, Podophyllum, Paeonia and Smilax, which were inadvertently or deliberately used as Wei Ling Xian in China markets [49]. ITS2 was also used to identify Chuan Mu Tong, its adulterants (e.g. Aristolochia and Akebia) and closely related species [50]. With ITS2, it is also easy to differentiate Chuan $\mathrm{Mu}$ Tong and other Clematis species. However, ITS2 cannot distinguish $C$. aethusifolia and $C$. pogonandra (subgenus Viorna), C. leschenaultiana and $C$. siamensis (subgenus Viorna), and C. tangutica and C. tibetana (subgenus Clematis).

Due to low resolving power, the actin I intron is not suitable for phylogenetic study of Clematis [51]. The nuclear (nr) ITS and five chloroplast (cp) DNA markers were used to deduce the evolutionary relationship of 33 Clematis species and related taxa [52]. The traditional subgenus Viorna and sect. Atragene (a subgenus in Wang and Li's system of 2005) were monophyletic, whereas taxa of subgenus Clematis, as well as those of subgenus Cheiropsis, did not form a clade. Substantial morphological divergence and meager nucleotide replacements within Clematis imply the recent radiation of the genus. Based on 75 species, sequences of the nrITS, the cp atpB-rbcL spacer, $p s b A$-trnH$\operatorname{trn} Q$ spacer and rpoB-trnC spacer regions were analyzed using parsimony, maximum likelihood and Bayesian inference methods [53]. Analyses of the combined data set by the three methods engendered similar trees. Ten major clades with various support values were found. The molecular inferences do not support prior morphology-based infrageneric classifications but suggest momentous evolutionary convergence in reproductive and vegetative characters in Clematis. Several branches represent geographically distinct groups. C. montana, C. chrysocoma and C. fasciculiflora of southwestern China, belonging to subgenus Cheiropsis, form clade $\mathrm{X}$ and are basal to other clades. C. rehderiana, C. leschenaultiana, C. ranunculoides, C. siamensis and $C$. lasiandra, distributed in southern, eastern and southeastern Asia and members of subgenus Viorna, form clade VIII and are basal to subgenera Clematis and Atragene. The members of subgenus Clematis, $C$. delavayi, $C$. peterae, $C$. heracleifolia, $C$. pinnata, $C$. brevicaudata, $C$. taiwaniana and $C$. apiifolia, are in clade VII, while $C$. patens is in clade VI. The raw species of Wei Ling Xian and their relatives, $C$. armandii and its relatives with similar drug efficacy are in clade V. Interestingly, $C$. akebioides, $C$. tangutica, C. tibetana, C. orientalis and C. serratifolia of clade I are closer to clade II (subgenus Atragene) than to other members of subgenus Clematis. However, relation- 
ships among some closely related species are not resolved, e.g., C. tangutica and C. tibetana, C. apiifolia and C. taiwaniana, C. brachiata and C. strigillosa, and C. uncinata and $C$. meyeniana, suggesting that these taxa may have diverged recently. Bayesian dating suggests a fairly ancient origin of the genus in the Oligocene (25.99 million years ago, mya) and a quite recent species radiation in the Miocene (7.81 mya). Geologic and climatic changes in the late Tertiary to Quaternary (2.588 mya-now) might be important for the speciation of Clematis, especially in East Asia. Long-distance spreading of the fruits by wind, water or animals and significant environmental adaptability might explain the current world-wide distribution and high species diversity.

Yunnan, China has the most Clematis species in the world and Hengduan Mountains of northwestern Yunnan are viewed as centers of origin, differentiation and endemism of the genus [42]. ITS and three cp markers, same as those of Xie et al. [53], were PCR amplified to study the phylogenetic relationship of Clematis [54]. Seventy-three species (132 samples) cluster into 18 clades. C. potaninii and $C$. fasciculiflora of subgenus Cheiropsis are basal to other taxa. Clade XV containing $C$. montana, $C$. gracilifolia, $C$. venusta and $C$. chrysocoma is close to clade XIV of subgenus Clematis. Clade XIII containing C. connata, C. rehderiana, C. lasiandra and clades XII and X containing other members of subgenus Viorna cluster together. Clade VIII represents subgenus Atragene and is closer to clade VII containing members of Meclatis, subgenus Clematis, which matches the results of Xie et al. [53]. C. hexapetala, $C$. terniflora, C. armandii, C. uncinata, $C$. crassifolia and $C$. patens cluster in clades IV and V. This study also suggests a recent species radiation. Most involved species are from southwestern China, particularly Hengduan Mountains of northwestern Yunnan. The massive diversification of modern Clematis occurred in Himalaya-Hengduan region during the uplift of the Qinghai-Tibetan Plateau and was manipulated by the global geologic and ecologic alterations during the late Tertiary [53]. Many plant groups underwent adaptive radiation, differentiation and speciation after migrating to this region, e.g. Pedicularis [55], Aconitum, Corydalis, Primula, Silene, Rhododendron [56], etc. Jiang [54] found that relationships among some closely related species of Hengduan Mountains are not decided, e.g., $C$. tangutica, C. akebioides and C. tibetana of subgenus Clematis, C. ranunculoides and $C$. yuanjiangensis of subgenus Viorna, suggesting that these taxa might be the result of rapid radiation and speciation. $C$. peterae and $C$. gouriana of southwestern China, as well as C. lasiandra and C. pseudootophora of Subgenus Viorna, might also come into being from species radiation. Morphology has diverged significantly in these pairs of species, but the molecular marker sequences have not yet diverged dramatically. It is motivating to study whether the chemical profile has also diverged or not, which could be helpful in choosing the source plant for the specific medicinal use. Moreover, natural hybridization may be common in Clematis, since artificial hybridization among closely related species or even among sections is easy and widely used in horticulture $[23,47]$. Many cultivars are obtained by hybridization and possess unique pharmaceutical components $[13,14]$. Due to the conflicting position of $C$. delavayi in the cpDNA and ITS trees, Miikeda et al. [52] suggested a hybrid origin of this species in the early evolution of the genus. Based on the incongruent position in the cpDNA and ITS trees, Jiang [54] inferred that $C$. delavayi, C. peterae, C. parviloba (subgenus Clematis), C. connata, $C$. rehderiana and $C$. ranunculoides (subgenus Viorna) might have a hybrid origin. ITS and psbA-trnH-trnQ can be used as DNA barcodes in the authentication of Clematis.

\section{Conclusions}

Clematis is a botanical source for various pharmaceutically active components, which has been used in conventional Chinese medicine for many centuries. Increasing interest in Clematis medicinal resources has led to additional discoveries of triterpenoid saponins, flavonoids, coumarins, alkaloids and many other compounds in various Clematis species, and to investigations on their chemotaxonomy, molecular phylogeny and pharmacology. However, around $90 \%$ of all 355 species have not been explored in phytochemistry, molecular biology and pharmacology, which is a gold mine of myriad medicinal compounds. Chemotaxonomy tries to classify and spot plants by discovering differences and similarities in their biochemical compositions, which is of great help in pharmaceutical resource discovery. However, the results of chemotaxonomy have to be cross-examined with those of molecular taxonomy and traditional morphologybased classification, in order to streamline the quality control and guarantee the authenticity of plant materials used in the clinical setting, research laboratory and pharmaceutical industry. More importantly, chemical and biological research of Clematis medicinal resources should not be restricted in the above aspects, e.g. the biosynthetic pathway of secondary metabolites has not been studied; the regulation of Clematis biological processes at genomic level, epigenomic level [63], transcriptional and post-transcriptional levels, and translational and post-translational levels is totally unknown, although it is essential for the conservation, sustainable development and utilization of the Clematis medicinal resources. The biological and chemical studies of Taxus [57] and Polygonum [58] with the use of omics technologies provide a paradigm of the active integration of various state-of-the-art methodologies into the early stage of the drug research and development. Systems biology and omics techniques will play an increasingly significant role in future medical research involving bioactive compounds of Clematis. 
This work was supported by Dalian Jiaotong University and Key Laboratory of Bioactive Substances and Resources Utilization of Chinese Herbal Medicine, Ministry of Education, China.

1 Wang W T, Li L Q. A new system of classification of the genus Clematis (Ranunculaceae). Acta Phytotaxo Sin, 2005, 43: 431-488

2 Sun F, Yang D P, Xiao P G, et al. Advance in chemical constituents of genus Clematis. Chin J Chin Mater Med, 2009, 34: 1-9

3 Hai W, Cheng H, Zhao M, et al. Two new cytotoxic triterpenoid saponins from the roots of Clematis argentilucida. Fitoterapia, 2012, 83: 759-764

4 He Y X, Li L, Zhang K, et al. Cytotoxic triterpene saponins from Clematis mandshurica. J Asian Nat Prod Res, 2011, 13: 1104-1109

5 Ding Q, Yang L X, Yang $\mathrm{H} \mathrm{W}$, et al. Cytotoxic and antibacterial triterpenoids derivatives from Clematis ganpiniana. J Ethnopharmacol, 2009, 126: 382-385

6 Peng C, Perera P K, Li Y M, et al. Anti-inflammatory effects of Clematis chinensis Osbeck extract (AR-6) may be associated with $\mathrm{NF}-\kappa \mathrm{B}, \mathrm{TNF}-\alpha$, and COX-2 in collagen-induced arthritis in rat. Rheumatol Int, 2012, 32: 3119-3125

7 Sun S X, Li Y M, Fang W R, et al. Effect and mechanism of AR-6 in experimental rheumatoid arthritis. Clin Exp Med, 2010, 10: 113-121

8 Fu Q, Zan K, Zhao M, et al. Triterpene saponins from Clematis chinensis and their potential anti-inflammatory activity. J Nat Prod, 2010, 73: 1234-1239

9 Hsieh M S, Wang K T, Tseng S H, et al. Using 18F-FDG microPET imaging to measure the inhibitory effects of Clematis chinensis Osbeck on the pro-inflammatory and degradative mediators associated with inflammatory arthritis. J Ethnopharmacol, 2011, 136: 511-517

$10 \mathrm{Wu}$ W, Xu X, Dai Y, et al. Therapeutic effect of the saponin fraction from Clematis chinensis Osbeck roots on osteoarthritis induced by monosodium iodoacetate through protecting articular cartilage. Phytother Res, 2010, 24: 538-546

11 Wang F, Tang Q L, Ma X L, et al. Research development on the chemical constituents from clematis spp. Chin Wild Plant Resour, 2009, 28: 1-6

12 Du Z Z, Yang X W, Han H, et al. A new flavone C-glycoside from Clematis rehderiana. Molecules, 2010, 15: 672-679

13 Hashimoto M, Suzuki T, Iwashina T. New acylated anthocyanins and other flavonoids from the red flowers of Clematis cultivars. Nat Prod Commun, 2011, 6: 1631-1636

14 Sakaguchi K, Kitajima J, Iwashina T. Kaempferol tri- and tetraglycosides from the flowers of Clematis cultivar. Nat Prod Commun, 2012, 7: 173-174

15 Chen R Z, Cui L, Guo Y J, et al. In vivo study of four preparative extracts of Clematis terniflora DC. for antinociceptive activity and antiinflammatory activity in rat model of carrageenan-induced chronic non-bacterial prostatitis. J Ethnopharmacol, 2011, 134: 1018-1023

16 Mostafa M, Appidi J R, Yakubu M T, et al. Anti-inflammatory, antinociceptive and antipyretic properties of the aqueous extract of Clematis brachiata leaf in male rats. Pharm Biol, 2010, 48: 682-689

17 Li Y, Wang S F, Zhao Y L, et al. Chemical constituents from Clematis delavayi var. spinescens. Molecules, 2009, 14: 4433-4439

18 Chen J H, Du Z Z, Shen Y M, et al. Aporphine alkaloids from Clematis parviloba and their antifungal activity. Arch Pharm Res, 2009, 32: 3-5

19 Peng H, Lv H, Wang Y, et al. Clematis montana lectin, a novel mannose-binding lectin from traditional Chinese medicine with antiviral and apoptosis-inducing activities. Peptides, 2009, 30: 1805-1815

20 Yan L H, Xu L Z, Wang Z M, et al. Two new phenolic glycosides from the stems of Clematis parviloba. Yao Xue Xue Bao, 2010, 45: $1527-1532$

21 Yang A M, Du J, Miao Z H, et al. Study on the chemical constituents from Clematis brevicaudata. Zhong Yao Cai, 2009, 32: 1534-1537

22 Wang X P, Qian H B, Huang J, et al. Comparative study on Clematis chinensis and Clematis uncinata by HPLC in vitro and in vivo. Lishizhen Med Mater Med Res, 2009, 20: 2224-2225

23 Johnson M. Slaktet Klematis. Södertälje: M. Johnsons Plantskola AB,
1997

24 Grey-Wilson C. Clematis the Genus. Oregon: Timber Press, 2000

25 Xiao P G, Wang F P, Gao F, et al. A pharmacophylogenetic study of Aconitum L. (Ranunculaceae) from China. Acta Phytotaxo Sin, 2006, 44: $1-46$

26 Xiao P G, Jiang Y, Li P, et al. The botanical origin and pharmacophylogenetic treatment of Chinese materia medica Beimu. Acta Phytotaxo Sin, 2007, 45: 473-487

27 Dennis W M, Bierner M W. Distribution of flavonoids and their systematic significance in Clematis subsection Viornae. Biochem Syst Ecol, 1980, 8: 65-67

28 Lebreton P. Flavonoids, taxonomic markers in the Ranunculaceae. Plant Med Phytother, 1986, 20: 275-286

29 Feng L F, Weng M Y, Tian F R, et al. Comparasion on total flavonoid content from aerial parts of 11 medicinal plants of Clematis L. Mod Chin Med, 2011, 13: 14-18

30 Fay M F, Dale P J. Condensed tannins in Trifolium species and their significance for taxonomy and plant breeding. Genet Resour Crop Evol, 1993, 40: 7-13

31 Jiang D, Shi S P, Cao J J, et al. Triterpene saponins from the fruits of Akebia quinata. Biochem Syst Ecol, 2008, 36: 138-141

32 Kim H K, Saifullah, Khan S, et al. Metabolic classification of South American Ilex species by NMR-based metabolomics. Phytochemistry, 2010, 71: 773-784

33 Muhammad Ishtiaq $\mathrm{Ch}$, He Q, Sun F, et al. Determination of taxonomic status of Chinese species of the genus Clematis by using high performance liquid chromatography-mass spectrometry (HPLC-MS) technique. Pak J Bot, 2010, 42: 691-702

34 Sun $\mathrm{F}, \mathrm{He} \mathrm{Q}$, Shi $\mathrm{P}$, et al. Characterization and identification of triterpenoid saponins in crude extracts from Clematis spp. by high-performance liquid chromatography/electrospray ionization with multi-stage tandem mass spectrometry. Rapid Commun Mass Spectrom, 2007, 21: 3743-3750

35 Sun F, He Q, Xiao P G, et al. Simultaneous quantification of five triterpenoid saponins in Clematis L. spp. by high-performance liquid chromatography with evaporative light scattering detection. Phytochem Anal, 2008, 19: 40-45

36 Huang W W, Kong D Y, Yang P M. Studies on lignan constituents of Clematis armandii Franch. Chin J Nat Med, 2003, 1: 199-203

37 Sun F, Cai Z, Yang D P, et al. Determination of triterpenoid saponins in Radix Clematidis and related Clematis species by high performance liquid chromatography-mass spectrometry. Chin J Anal Chem, 2010, 9: 1293-1298

38 Sun F, Cai Z, Muhammad Ishtiaq Ch, et al. Distribution of the triterpenoid saponins and chemotaxonomy of the genus Clematis L. by high-performance liquid chromatography-mass spectrometry. Biochem Syst Ecol, 2010, 38: 1018-1025

39 Muhammad Ishtiaq Ch, Abdul Samad M, Wang Y, et al. Proteins as biomarkers for taxonomic identification of traditional Chinese medicines (TCMs) from subsection Rectae genus Clematis from China. World Appl Sci J, 2010, 8: 62-70

40 Shi S P, Dong C X, Jiang D, et al. Macrocyclic glucosides from Clematis mandshurica and Clematis hexapetala. Biochem Syst Ecol, 2006, 35: 57-60

41 Hao D C, Chen S L, Xiao P G, et al. Authentication of medicinal plants by DNA-based markers and genomics. Chin Herb Med, 2010, 2: $250-261$

42 Jiang N, Guan K Y, Wang Z L. Species diversity and geographical distribution of Clematis (Ranunculaceae) in Yunnan. Acta Bot Yunnan, 2007, 29: 145-154

43 Pu C X, Yang Z Y, Liu X L. RAPD analysis of 12 species of Clematis. J Yunnan Univ Trad Chin Med, 2008, 31: 37-41

44 Ma H M, Zhang B L. Comparison among families of Mutong. Chin J Chin Mater Med, 2002, 27: 412-418

45 Chen W Y, Pu C X. Resource investigation of medicinal species of Clematis in Yunnan province. J Yunnan Coll Trad Chin Med, 2006, 29: 31-33

46 Guo J L, Ren Y, Chen L, et al. Authentication of Caulis clematidis armandii ("Chuanmutong") and differentiation of its common adul- 
terants using RAPD and SCAR markers. J Med Plant Res, 2010, 4: 697-701

47 Yuan T, Wang L Y, Roh M S. Confirmation of Clematis hybrids using molecular markers. Sci Horti, 2010, 125: 136-145

48 Jiang M, Zhou Y Q, Li R R. ITS sequence analysis of eight medicinal plants in Clematis L. Chin Trad Herb Drug, 2011, 42: 1802-1806

49 Zeng $\mathrm{X}, \mathrm{Li} \mathrm{L}, \mathrm{Ye} \mathrm{N}$, et al. Molecular identification of radix et rhizome clematis and its adulterants based on ITS2 DNA barcode. Global Trad Chin Med, 2011, 4: 264-269

50 Liu M Z, Li M N, Yao H, et al. Molecular identification of Clematidis Armandii Caulis and its adulterants and closely related species by ITS2 sequence. Glob Trad Chin Med, 2011, 4: 446-450

51 Slomba J, Garey J R, Essig F B. The actin I intron-a phylogenetically informative DNA region in Clematis (Ranunculaceae). Sida, 2004, 21: 879-886

52 Miikeda O, Kita K, Handa T, et al. Phylogenetic relationships of Clematis (Ranunculaceae) based on chloroplast and nuclear DNA sequences. Bot J Linn Soc, 2006, 152: 153-168

53 Xie L, Wen J, Li L Q. Phylogenetic Analyses of Clematis (Ranunculaceae) based on sequences of nuclear ribosomal ITS and three plastid regions. Syst Bot, 2011, 36: 907-921

54 Jiang N. Molecular phylogeny and reproductive biology of Clematis (Ranunculaceae). Dissertation for the Dorctoral Degree. Kunming: Kunming Institute of Botany, CAS, 2010

55 Yang F S, Wang X Q, Hong D Y. Unexpected high divergence in
nrDNA ITS and extensive parallelism in floral morphology of Pedicularis (Orobanchaceae). Plant Syst Evol, 2003, 240: 91-105

56 Luo Y, Zhang F M, Yang Q E. Phylogeny of Aconitum subgenus Aconitum (Ranunculaceae) inferred from ITS sequences. Plant Syst Evol, 2005, 252: 11-25

57 Hao D C, Ge G B, Xiao P G, et al. The first insight into the tissue specific taxus transcriptome via Illumina second generation sequencing. PLoS One, 2011, 6: e21220

58 Hao D C, Ma P, Mu J, et al. De novo characterization of the root transcriptome of a traditional Chinese medicinal plant Polygonum cuspidatum. Sci China Life Sci, 2012, 55: 452-466

59 Zhao M, Tang H F, Qiu F, et al. Triterpenoid saponins from Clematis argentilucida. Biochem Syst Ecol, 2012, 40: 49-52

60 Dong F Y, Cui G H, Zhang Y H, et al. Clematomandshurica saponin E, a new triterpenoid saponin from Clematis mandshurica. J Asia Nat Prod Res, 2010, 12: 1061-1068

61 Liu L F, Ma X L, Wang Y X, et al. Triterpenoid saponins from the roots of Clematis chinensis Osbeck. J Asian Nat Prod Res, 2009, 11: 389-396

62 Yan L H, Xu L Z, Lin J, et al. Triterpenoid saponins from the stems of Clematis parviloba. J Asian Nat Prod Res, 2009, 11: 332-338

63 Ngezahayo F, Wang X L, Yu X M, et al. Habitat-induced reciprocal transformation in the root phenotype of Oriental ginseng is associated with alteration in DNA methylation. Chin Sci Bull, 2011, 56: 1685-1690

Open Access This article is distributed under the terms of the Creative Commons Attribution License which permits any use, distribution, and reproduction in any medium, provided the original author(s) and source are credited. 